\title{
Non Expensive 3D Documentation and Modelling of Historical Object and Archaeological Artefacts by Using Close Range Photogrammetry
}

\author{
Karel Pavelka ${ }^{1}$, Jan Řezníček ${ }^{2}$, Zdeňka Bílá ${ }^{2}$, Lucie Prunarová ${ }^{2}$ \\ ${ }^{1}$ Head of Laboratory of Photogrammetry, Department of Geomatics \\ ${ }^{2}$ Department of Geomatics \\ Czech Technical University in Prague, Faculty of Civil Engineering \\ 16629 Thákurova 7, Prague, Czech Republic \\ pavelka@fsv.cvut.cz \\ jan.reznicek1@fsv.cvut.cz \\ zdenka.bila@fsv.cvut.cz, lucie.prunarova@fsv.cvut.cz
}

\begin{abstract}
Nowadays, there are two main approaches to cultural heritage documentation: a precise documentation by several techniques such as professional close range photogrammetry, classical geodetical measurement and 3D scanning, or a simple documentation using non expensive devices and instruments, often based on free software. In many projects it is not possible to use precise and expensive instruments for time, transportational, financial and authoritative permission reasons. At the Laboratory of Photogrammetry at the CTU Prague, we are focused on both types of documentation and the necessary visualisation of outputs; the long-term and very important aim of our research in this field is to develop small, inexpensive devices and test appropriate technology for the $3 D$ documentation of cultural heritage objects. There is our prototype of an optical correlation system, which uses a motorised calibrated digital camera on a linear base. The second part shows several open source photogrammetric systems compared with Photomodeler PMSC and Agisoft Photoscan software. On a case project, based on our own data from German-Czech expeditions in Peru, the simple photogrammetric documentation of a small archaeological object joined with reverse engineering has been demonstrated.
\end{abstract}

Keywords: Culture heritage, digital photogrammetry, 3D documentation, digital camera, image correlation, Photosynth, PMSC, ARC 3D, OKS

\section{Introduction}

At the Czech Technical University in Prague, in the framework of a co-operation between the Laboratory of Photogrammetry on the Faculty of Civil Engineering, Faculty of Physical and Nuclear Engineering (historical objects and artefacts dating) and other institutions such as the Department of Archaeology of the West Bohemia University or regional institutes for historical objects, care, modern simple methods of 3D objects documentation are tested. 
The quality and resolution of actual standard or half-professional digital cameras is on a high level and it generally reaches 10-20Mpixels. The current possibilities of computer equipment are not so restrictive in the processing of huge data as some years before. You can make an applicable 3D documentation with an ordinary digital camera and special software working with image correlation techniques, which can, in some cases, replace precise and expensive 3D scanning (made by a laser scanner or a triangulation scanner). A lot of free software or services are nowadays available. On the web, there are software's that produce a cloud of points from photos. Of course there are several professional software systems for this activity on the market. Generally, all these software are certainly under rapid development and in the near future we can wait on qualitative changes. At the Laboratory of Photogrammetry, we have developed our own system, based only on digital camera and images correlation software solution (OKS). The advantage of this system lies on incremental image correlation with very high position control. The output doesn't have correlations errors (noise, which is typical by using of two images for correlation only - e.g. in Photomodeler). Of course, it is necessary to edit created clouds of points and fill missing parts (e.g. in software Geomagic). The results from different systems based on image correlation techniques are compared and discussed in chapter 2.2. First, our experience with free software solutions and their utilisation is described; the second part is focused on Photomodeler Scanner or Agisoft Photoscan software's possibilities and outputs (chapter 4). The last part shows the results made by the OKS system (chapter 3). Most of the results after editing can be printed on a 3D printer.

\section{Photogrammetry}

\subsection{Information from digital images}

Our team is focused on the processing of digital photos. As mentioned, the resolution of actual half-professional or professional digital cameras is certainly sufficient for ordinary project and reaches generally tens of thousands of pixels (the resolution has increased ten times in the last ten years). The computer performance is high; it is not a problem to process hundreds of digital photos based on a fully automated process of image orientation, image correlation, creating of dense cloud of points and texturing of 3D results. For the creation of 3D models it is enough to use an ordinary digital camera and special software only. In today's possibility we investigated a small project based on images of archaeological finds from Palpa/Peru (see chapter 4).

For image data processing to 3D model or cloud of points, there are several approaches. Photogrammetrically based software like PMSC needs a precise camera calibration for the processing and a special set of photos taken ( a combination of photos with convergent and parallel shot axis - depending on the type of processing); geodetically measured control points are appropriate. The other type is software, which works as a web service; no additional information is necessary, the processing is focused on photos from ordinary cameras and the user cannot affect the result (black box for users). The output is usually a 3D model or points cloud without scale. The last type of software is based on computer vision. Any camera parameters are acceptable, but all photos must have a big overlap between each other. The processing is fully or semi-fully automated and it is possible change some processing parameters. Outputs are 3D models with scale (Agisoft Photoscan). 


\subsection{Software for image correlation}

On the market today, there are several special software systems for creating of 3D models direct from images. From the photogrammetry point of view, the best known is Photomodeler (version 6 Scanner, version PMSC 2010 and last PMSC 2012), but its method of point clouds creation is not ideal. The points cloud is generated only from two photos with approximately parallel frame axes; there is no position control and many points are on wrong position. For complex modelling, a set of these photos is needed and the operator must select the appropriate combination. On the other hand, it is possible to influence the output by parameters selection. Nowadays, (2013) Agisoft Photoscan gives better outputs and is frequently cited in the creation of 3D models since 2011. As a free service on the web or free software, there is a lot of software for producing a cloud of points from images or directly from 3D models. Our survey is based on small projects in our Laboratory of Photogrammetry, bachelor and diploma thesis (Prunarová, 2010, Šedina 2012). The following text is not a complex description of today's possibilities or services, but a demonstration of using only on a small object (a funeral container documented by German-Czech expedition to Peru in 2008 and in 2012).

ARC 3D Webservice (Katholieke Universiteit Leuven) makes a 3D model from an image sequence taken by a digital uncalibrated camera. It consists from two modules: Image Uploader for image uploading to the server and Model viewer (Fig.1) for processed object visualisation and its export to other formats (for example VRML). After processing you get an E-mail and the textured 3D model can be downloaded. No model editing is possible (version 2010, Fig.2). It was discovered that this system was not fully utilizable for our projects. Of course, our image set was not ideal. Our first case project consisted from 30 images only (the bottom part was missing); the object is a funeral container from Nazca time (100 - 650 A.C., Peru) from a private collection.
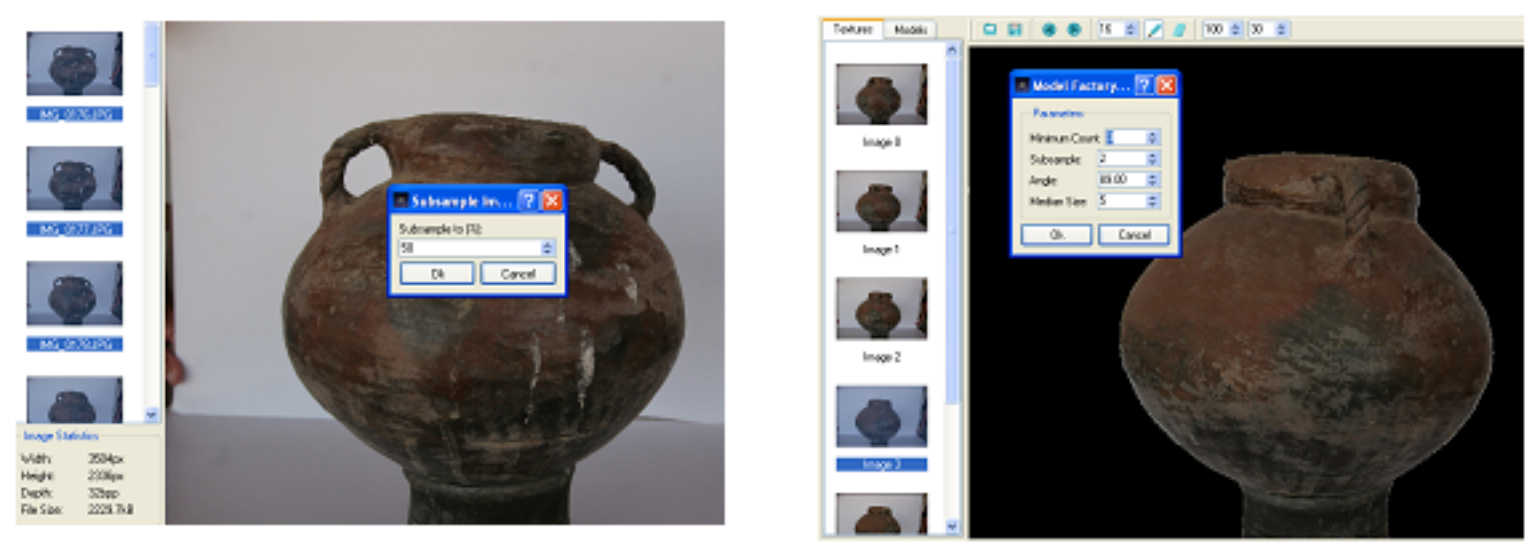

Figure 1: Image Uploader and Modelviewer

Photosynth software (under Microsoft) creates panorama images or virtual models using free client software. After the processing of images, a virtual model is exposed on a web site (http://photosynth.net); currently no other facilities are free of charge (Fig.3).

For the modelling and 3D printing of the container, original points are needed, not only an exposure of the partial model on the Web. After a problematic conversion, only 11000 points were processed from the images and then edited by using Geomagic software (Fig.4). These 

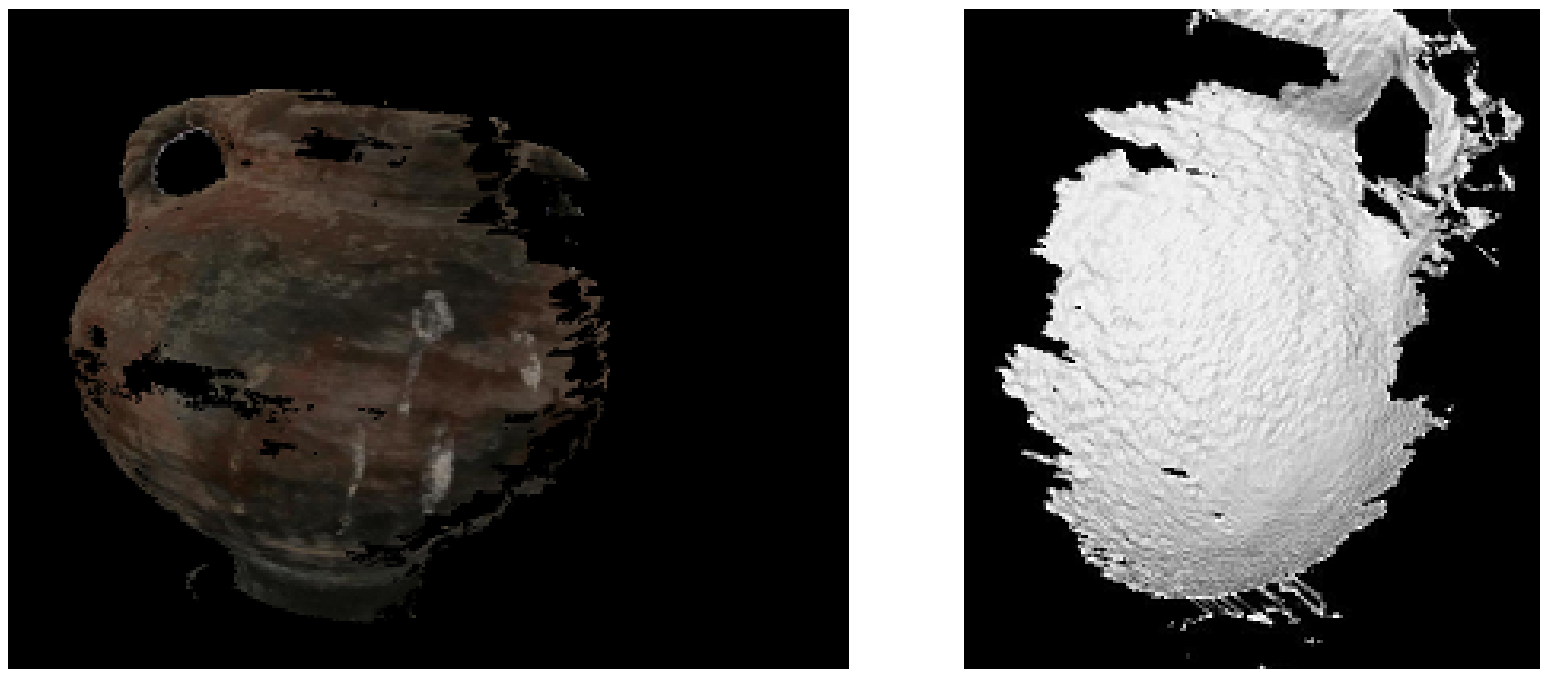

Figure 2: Processing and visualisation of a funeral container
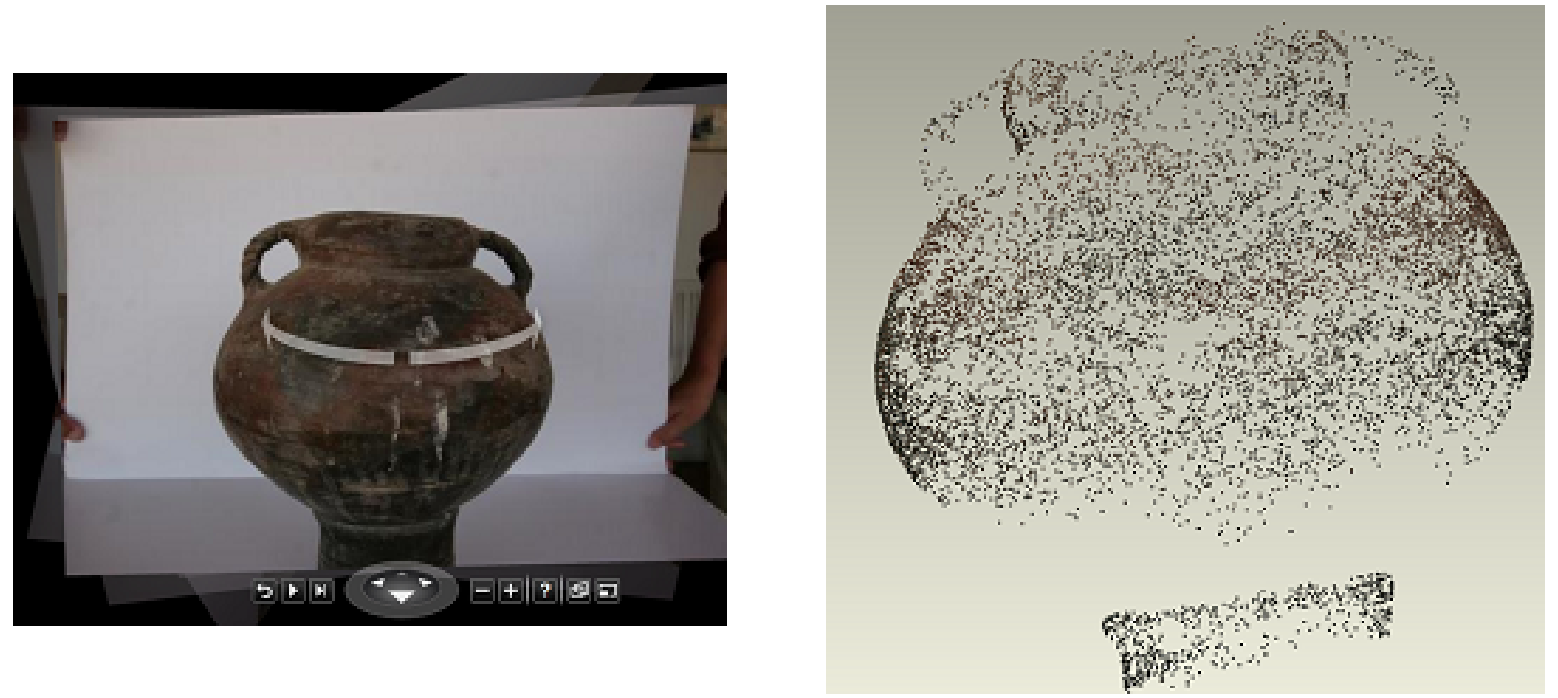

Figure 3: Processing by Photosynth software

points are used in the correlation process and are not a typical dense cloud of points. No accurate characteristic is given in this solution.

Insight 3D is an open source application; it computes camera positions, camera parameters and after them creates points cloud by using image correlation. A module for editing, meshing and texturing is attached.

MeshLab is an open source application for processing, editing and visualisation of cloud of points. It is not the prime aim to describe all the existing software; our project was conducted by students in 2010-2012 (Prunarová, 2010, Šedina, 2012, Bílá, 2012) and we tested only some of them. Other projects or works on this field describe products like Bundler, 123Catch (Marčiš, 2013). 

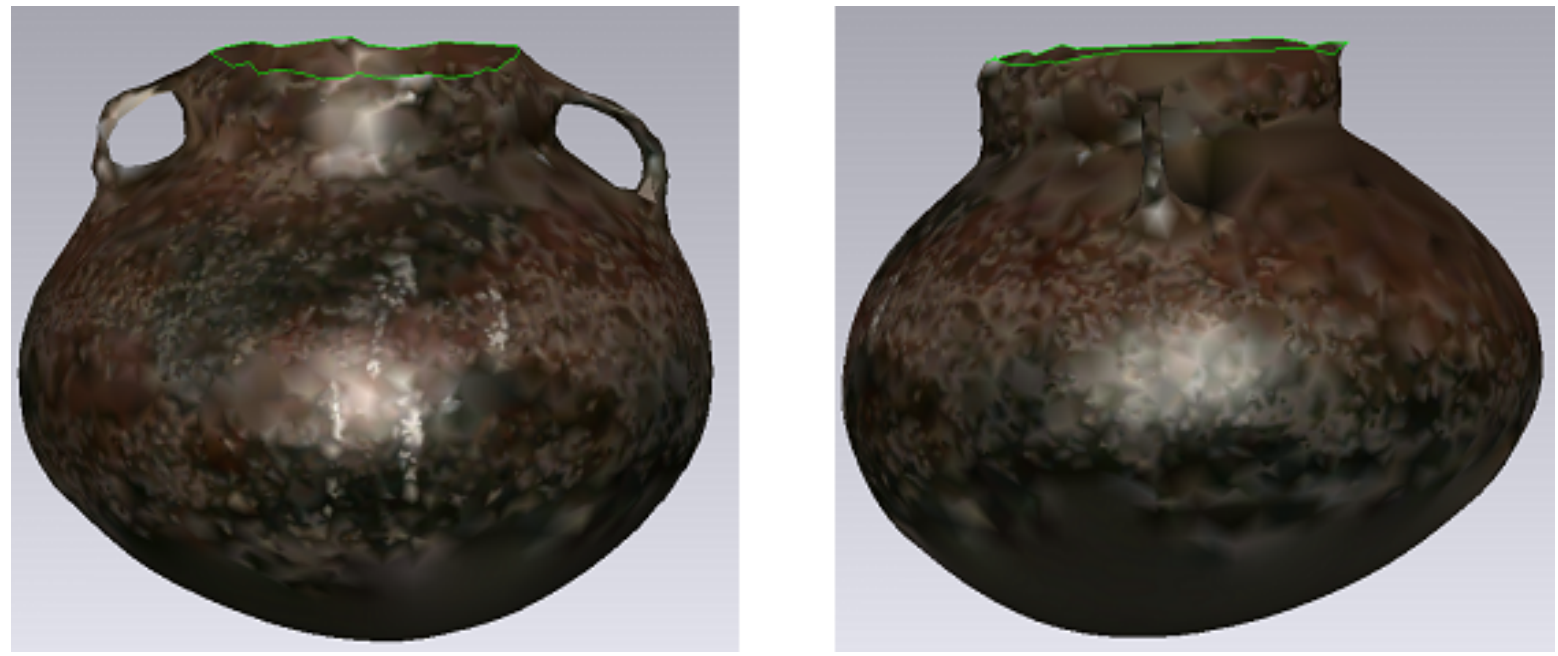

Figure 4: Final model created using Photosynth and Geomagic software

\section{University developed instrument and software OKS (Optical Correlation Scanner)}

At the Laboratory of Photogrammetry, we have developed our own system, based only on digital camera and images correlation software solutions (OKS, Fig.5). Optical correlation scanner consists of one calibrated camera, a photo-base with a moving camera-holder, a tripod, and software written in Matlab language. OKS was designed to be universal; by changing the base length, it is possible to measure short-distance objects, as well as long-distance (the base is variable up to 1 meter, Fig.6). The images are taken with a very short step (usually 5 or 10 $\mathrm{cm}$ ) in order to have a good correlation. The basic idea of our approach is such that each point should be matched on more than two images. Given the two image point correspondences, we do not have control of any of the estimates. The third image point correspondence is necessary for validating the correctness of point match. More image point correspondences increase the total precision and reliability of point match. On Fig.6 and Fig.7 case project solved using OKS in Velenice village is shown. Original to this solution is the output in 3D without noise points; spatial accuracy of points is from a distance of about $2-3 \mathrm{~m}$ better than $1 \mathrm{~mm}$.

\section{Case study}

OKS runs good, but it is a prototype and a university solution written in Matlab (the processing runs many hours); it needs a linear base and tripod. Measurement with this prototype is not simple. As a small case project of the above-mentioned documentation technique (easy to use) a funereal container from Palpa village surroundings (Peru) has been utilised (Fig.9). During the German-Czech expedition Nasca/Peru in 2008, only 22 hand-held photos were taken within a 10 minute time span (RAW image format using calibrated camera Canon $20 \mathrm{D}$ equipped with $22 \mathrm{~mm}$ lenses). The camera position was unchanged as we rotated the container (Fig.8). Only one distance was measured (neck diameter for object scale). We discovered later that this was not an ideal configuration (missing bottom part). In this project, the Photomodeler Scanner software ver.2010 was utilised. For creating the model, approxi- 


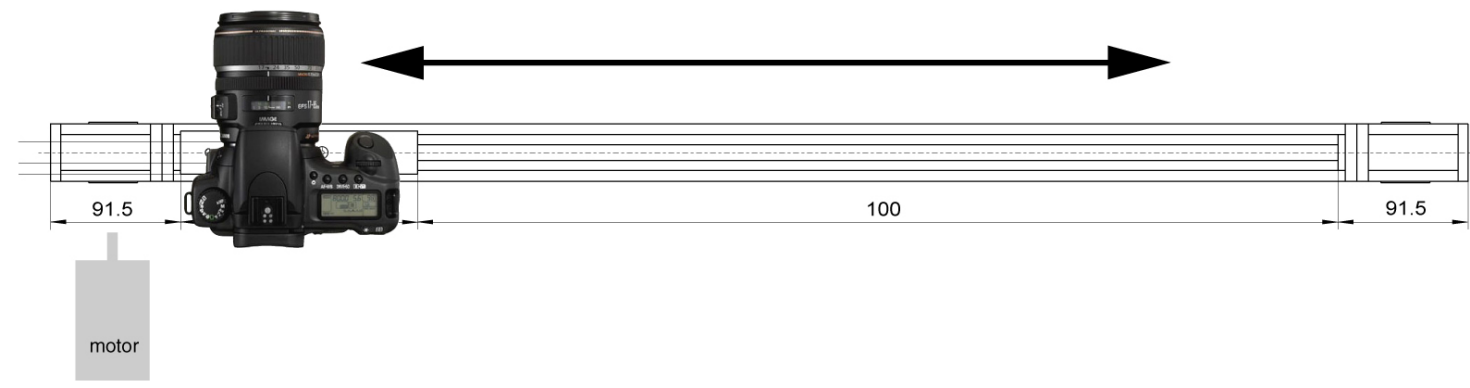

Figure 5: Image sequence for improving image correlation process

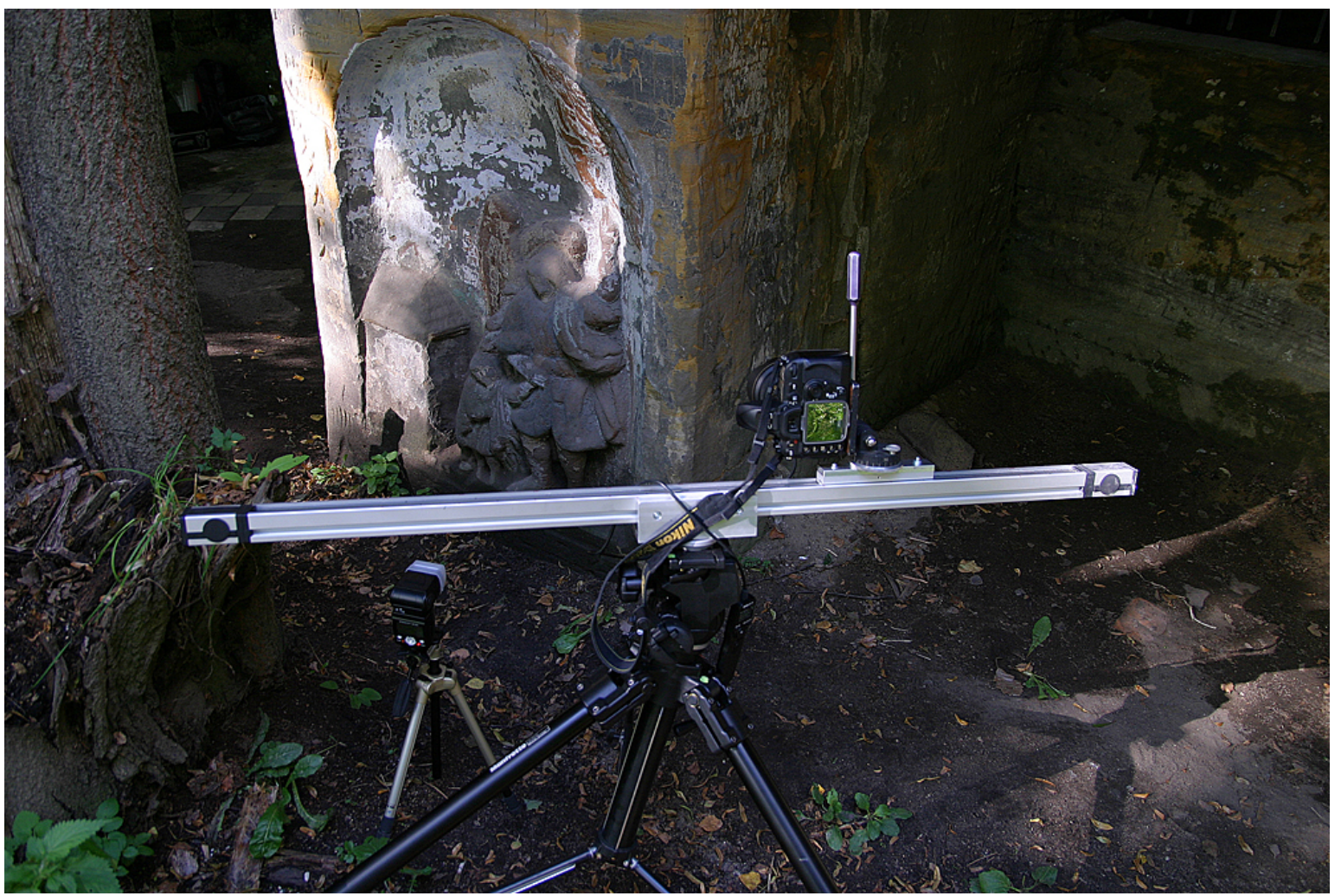

Figure 6: Optical Correlation System (OKS)

mately 200 tie-points were used as well as all of the 22 images captured (Prunarová, 2010). In ver.2012 the model creation was better and it could be automated. After the computing of image orientations, the function Creating Dense Surface was used and 24 points clouds were generated. The next processing was made in Geomagic software, which had better functions for other processing (Fig.10, 11). 


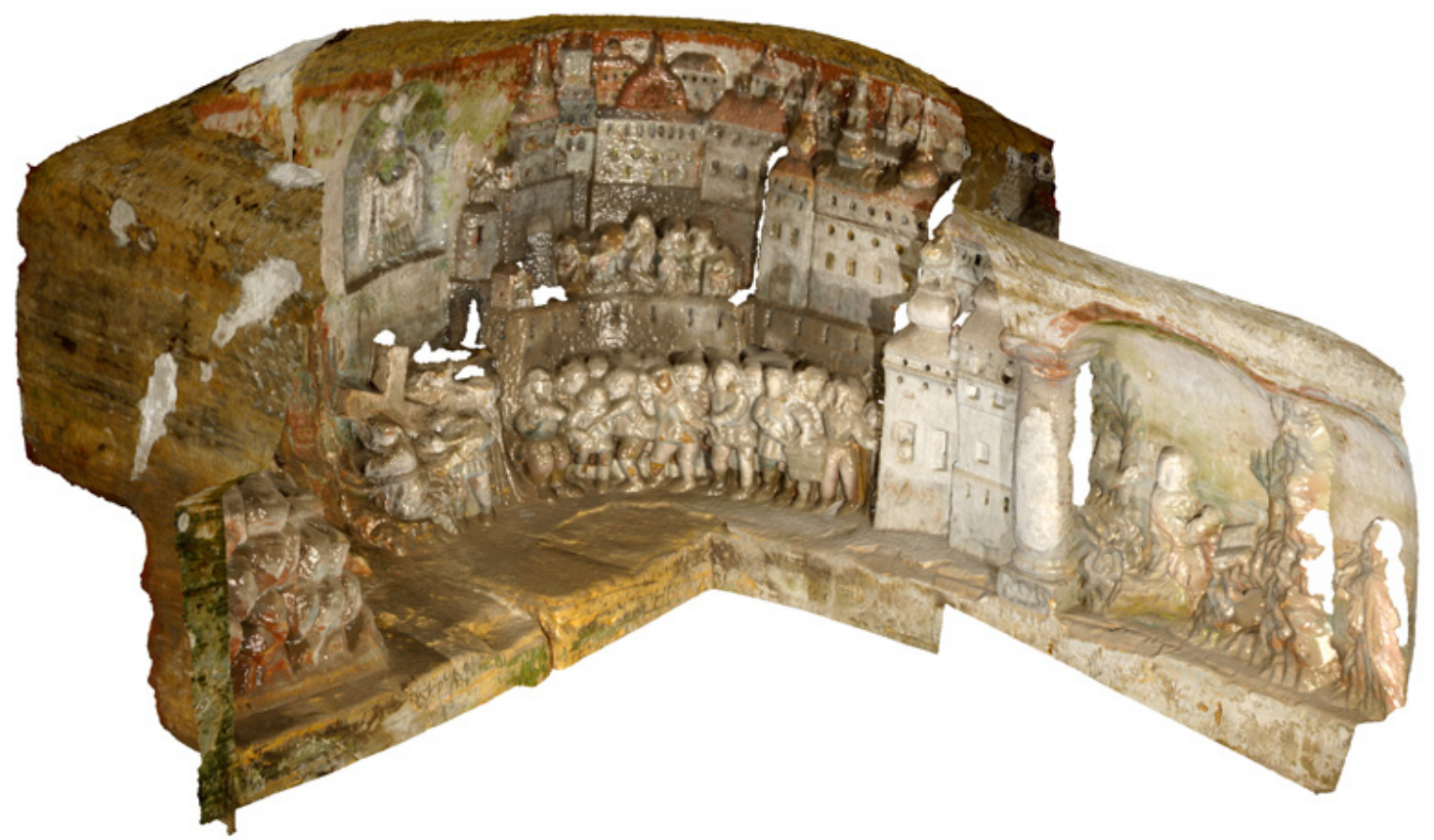

Figure 7: Final 3D model of one part of the relief with texture (Baroque-age relief near Velenice village in the Czech Republic)
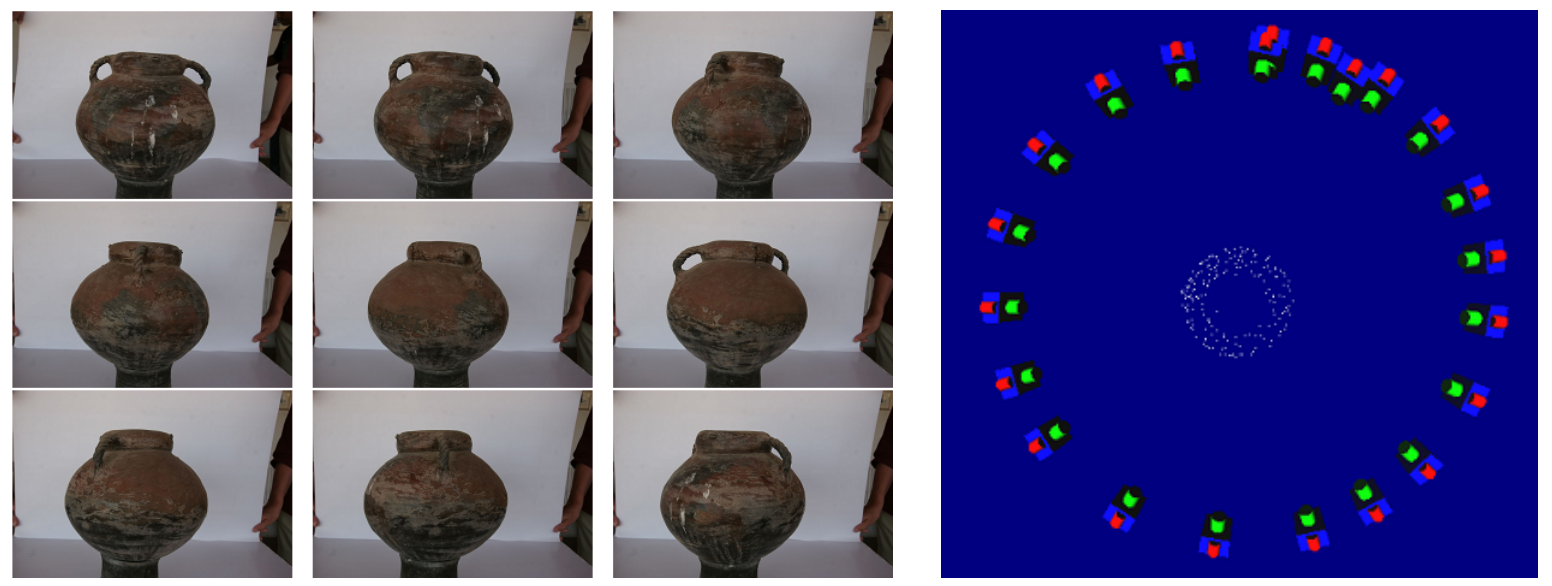

Figure 8: Original images (example - 9 photos from 22); images and their configuration in Photomodeler software.

\section{Editing of image correlation outputs}

Of course, it is necessary to edit created clouds of points and fill the missing parts (various software for laser 3D scanning are utilizable); we frequently use the Geomagic software (Fig.12). For the creation of a (bounded) closed object, the meshing of points is necessary. In this case, about 500000 triangles were created, but some parts were missing (bad photos configuration) and it has been determined that not only a radial image sequence is enough for complex documentation (Fig.12). The final supplemented output is on Fig.13 (Geomagic). In 


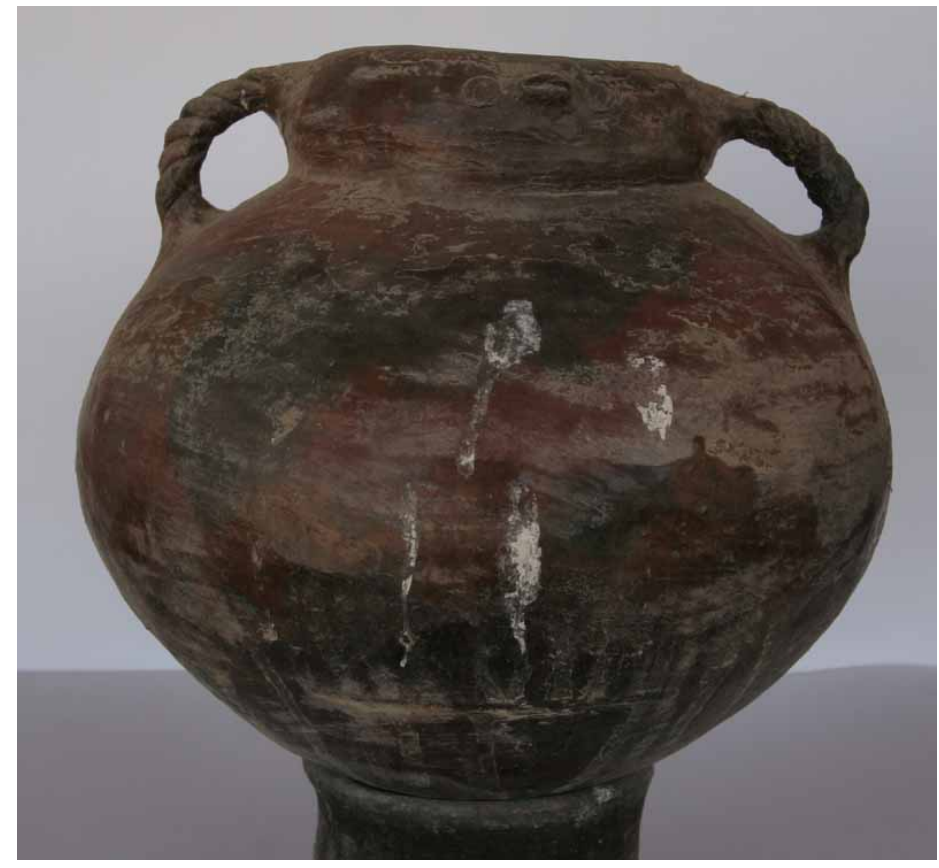

Figure 9: An example from an original photo sequence.
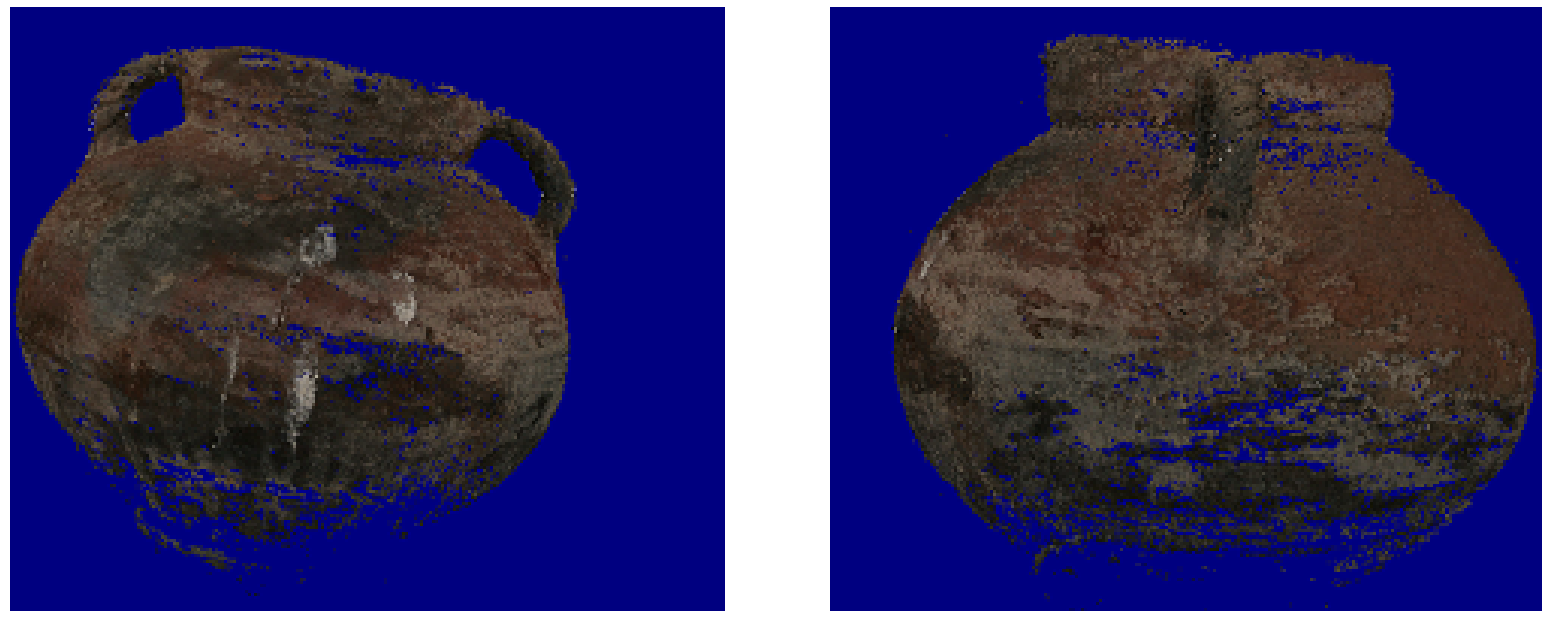

Figure 10: Generated points cloud from image-pairs.

Photomodeler, there are many precise characteristics. The standard deviation characteristic seems suitable; in our case it reaches values better than $0,2-0,4 \mathrm{~mm}$ which is too optimistic; so the model is certainly not good. From our point of view, the more successful techniques are as follows: 1) a sequence of images with convergence axis for camera position and orientation computing 2) a set of roughly stereo pairs around the objects minimally in two axes.

\section{3D print of facsimile}

The final model, after extensive editing, was printed on the $3 \mathrm{D}$ printer Zprint 450 , which is located at the Laboratory of Photogrammetry on CTU in Prague. This 3D printer make a 


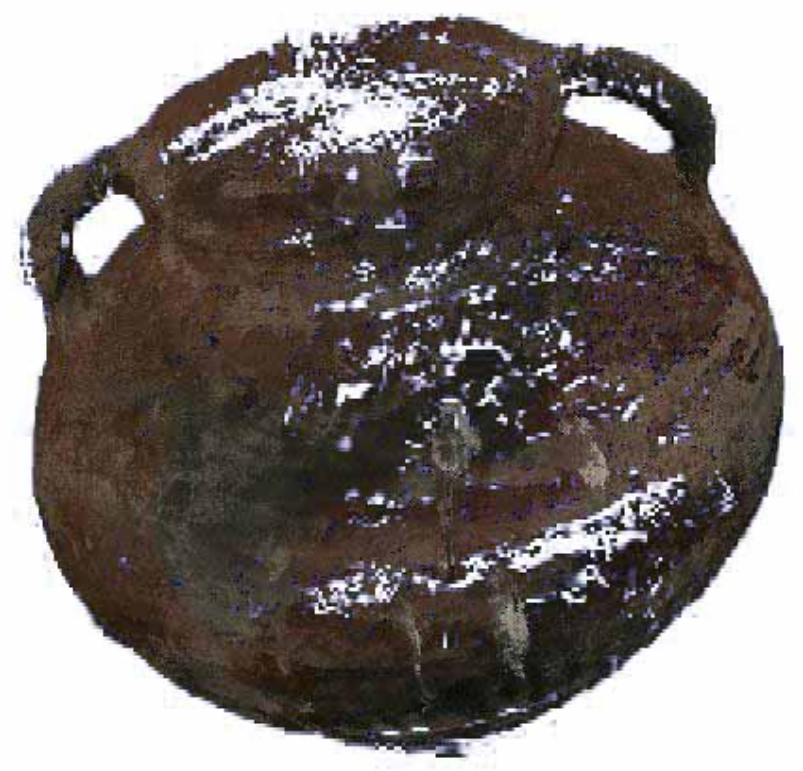

Figure 11: The rendered points cloud in Photomodeler Scanner 2010 software.
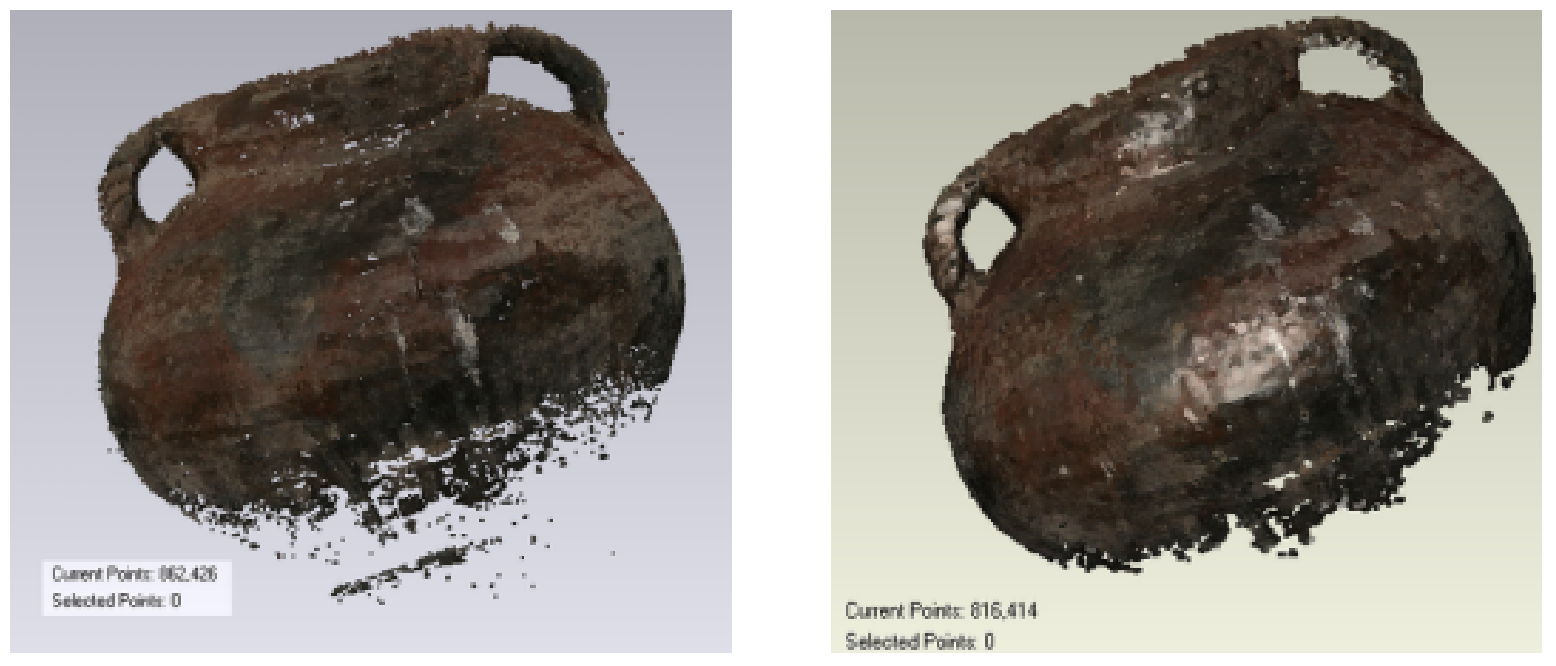

Figure 12: Textured cloud of points in Geomagic software

3D print from a CAD model by using the "layer by layer" technique from composite materials (like plaster); the layer is created by depositing a liquid binder onto thin layers of powder (the layer have only $0.1 \mathrm{~mm}$ thickness and can be coloured from original photos). The final output is on Fig.14.

\section{Agisoft Photooscan}

Based on our last expedition to Peru in 2012, we collected a large amount of photographic material. Because of financial and transportation reasons we used only the calibrated camera 

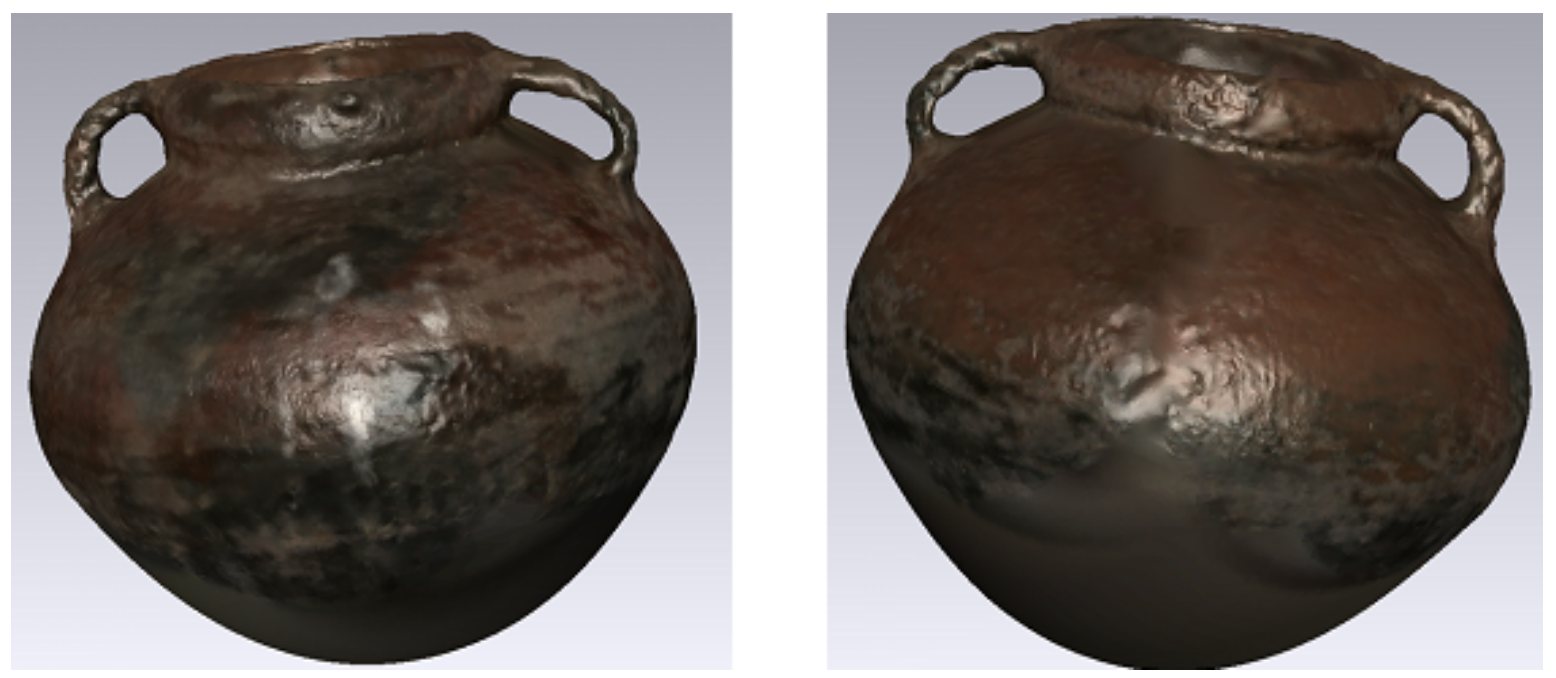

Figure 13: Final model of the funereal container

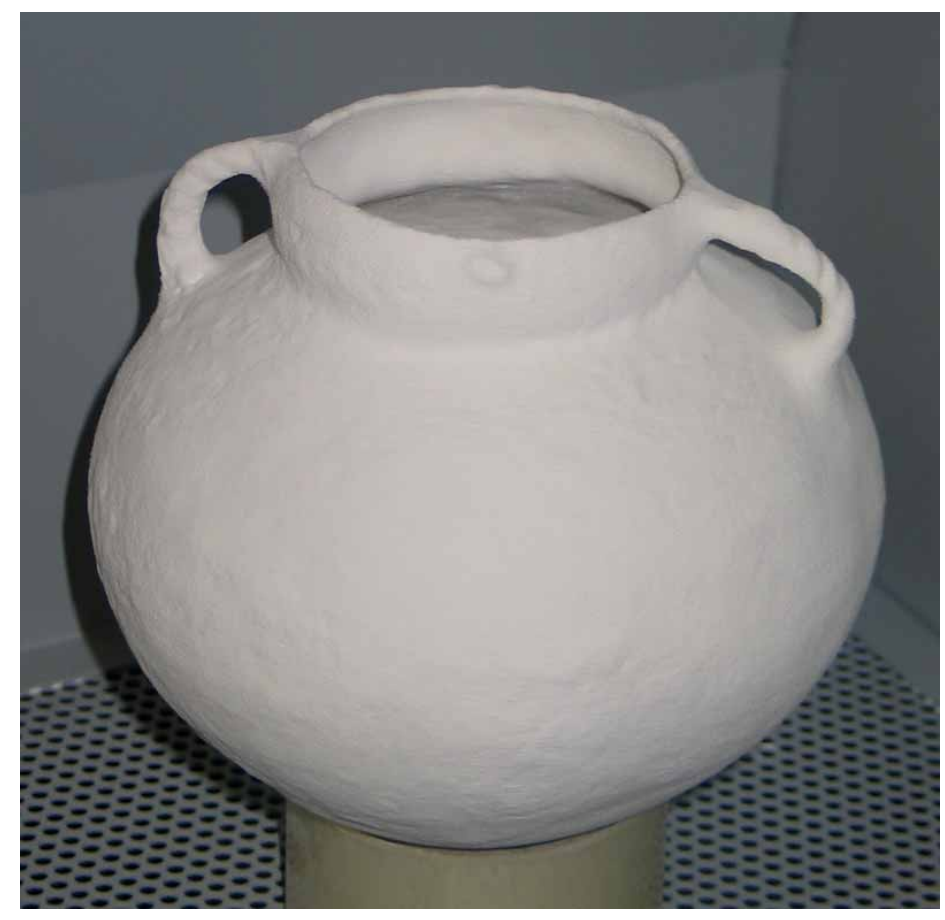

Figure 14: The final model created by 3D printer Zprint 450 (after editing in Geomagic software)

Canon 20D, common GNSS navigation, and tape for basic distance measuring. Like in 2008, we documented a ceramic vessel from Nazca time in Palpa city (Fig.15). This archaeological find is of course not possible to transport to the Czech Republic. Based on our experience, we took around 50 images (the vessel rotated step by step around two axes). Next, processing was made in Agisoft Photoscan. After masking the main object on images, the process was automatic. The output was textured and transformed to the 3D Adobe Acrobat viewer 
(Fig.16). The original model has 2 millions points and the accuracy reaches (standard deviation) $0.4-0,5 \mathrm{~mm}$, which seems to be optimal for this purpose and credible. The new Agisoft Photoscan version has the spatial transformation to the control points set. After this we get a precise characteristic.
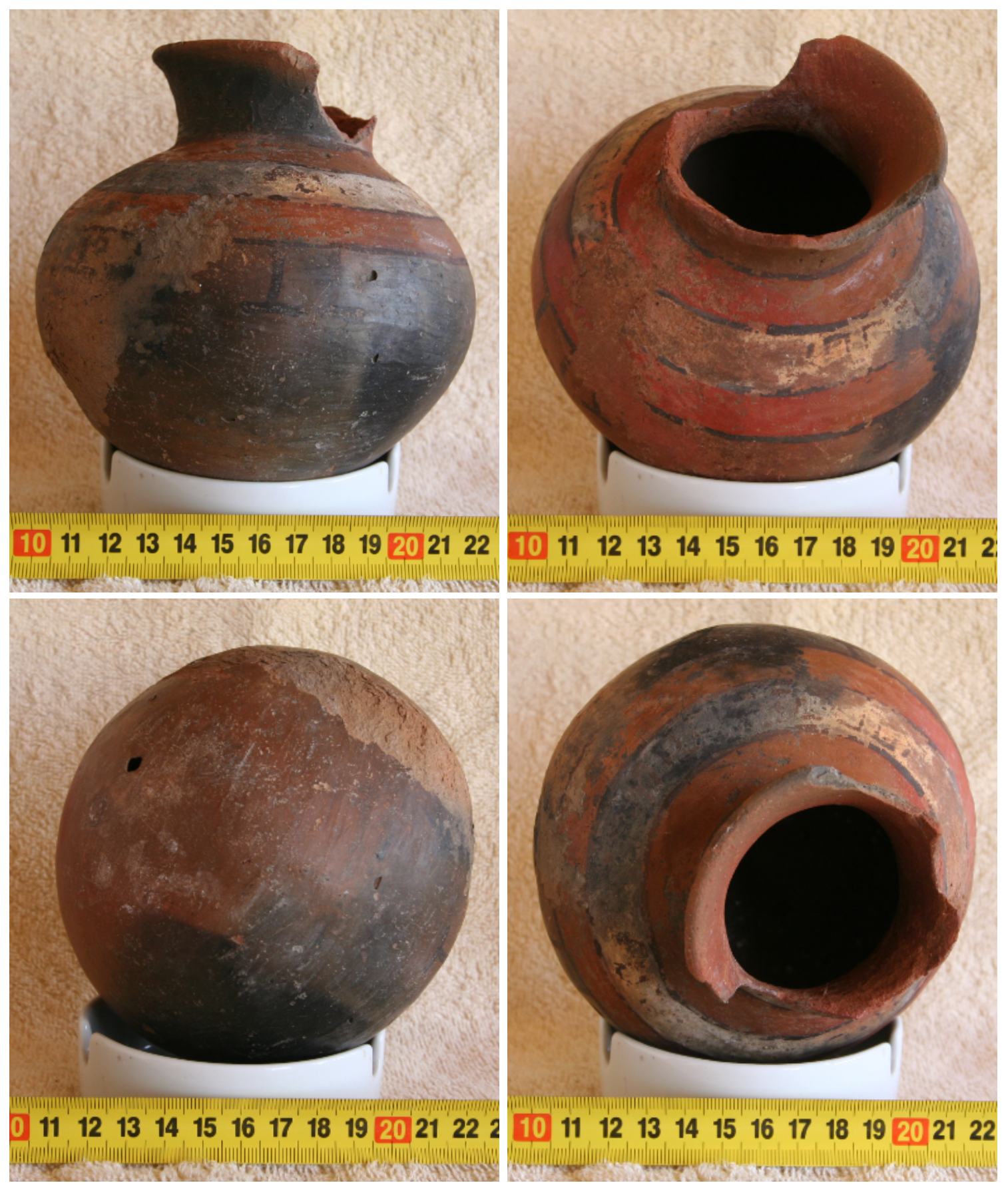

Figure 15: Photos of ceramic vessel in Palpa. 


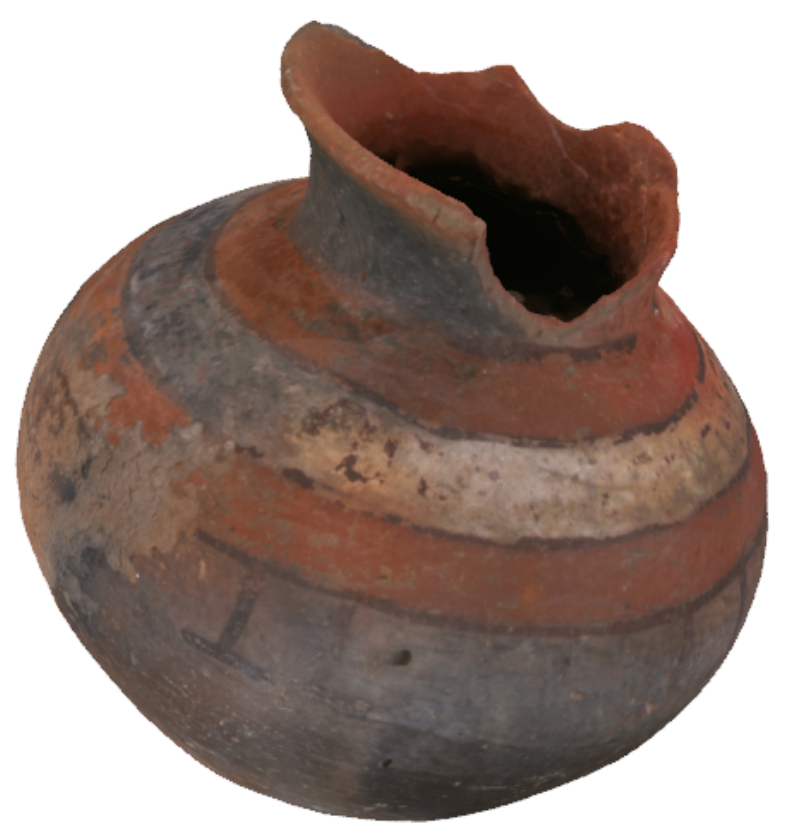

Figure 16: Rotating 3D model in Adobe Acrobat viewer.

\section{Conclusion}

This article is focused on the simple documentation of cultural heritage using modern digital photogrammetry and computer vision technology. The aim is to demonstrate the easy to use technology that allows for the full or semi-automated external orientation of images, camera calibration and creation of 3D models from images based on image correlations technique. The experience with the free software solution for image correlation techniques and their utilisation in close range photogrammetry and historical objects documentation is described. Our university solutions OKS has been introduced. In the second section we focused on Photomodeler Scanner and Agisoft Photoscan software's possibilities and outputs, and the last section represents the result of images edited in the Geomagic software. The created and edited 3D model was printed on the 3D printer. We can say that nowadays it is possible to use simple photogrammetric techniques for precise non-expensive documentation in close range photogrammetry. It is a very good sign for cultural heritage documentation and visualisation. With good configuration and quality photos taken by digital camera, the accuracy (standard deviation) reaches from 0.2 to $1 \mathrm{~mm}$ from distances $1-5 \mathrm{~m}$. In larger and more distant objects the accuracy is worse, but still acceptable. All of the images must have the necessary overlap e.g. $80 \%$ (greater than by aerial photogrammetry), images with a low convergent axes are appropriate (for better image correlation). Finally, there now exists a lot of software which can be used in the cultural heritage documentation area. The user can choose according to their capabilities, effort, and documented object characteristics.

\section{Acknowledgements}

This project was sponsored by Ministry of Education Research Scheme MSM6840770040. 


\section{References}

[1] Pavelka K., Dolanský T. 2003. Using of non-expensive 3D Scanning Instruments for cultural heritage documentation, Symposium CIPA, WG 6, Antalya, Turkey, p.237-241.

[2] Koska, B., Pospíšil, J., Štroner, M.. 2006. Innovations in the Development of Laser and Optic Rotating Scanner LORS. XXIII International FIG Congress. Munich, Germany. ISBN 87-90907-52-3

[3] Pavelka, K., Řezníček, J. 2009. Culture Heritage Preservation With Optical Correlation Scanner, 22nd CIPA Symposium, Symposium proceedings, Kyoto, Japan

[4] Prunarová, L.2010. Creating of historical object spatial documentation and its visualisation, Bachelor thesis, (in Czech), CTU in Prague, Faculty of Civil Engineering.

[5] Šedina, J. 2012. Comparation of 3D scanning techniques with point cloud created by using of correlation method in digital photogrammetry. Master thesis (in Czech), CTU in Prague, Faculty of Civil Engineering.

[6] Marčišš, M.. 2013. Ochrana a obnova kultúrneho dedičstva metódami digitálnej fotogrammetrie, doctoral dissertation (in Slovak). Slovenská technická universita v Bratislave, Stavebná fakulta, SvF-13417-51610

[7] Řezníček, J., Pavelka, K., 2008. New Low-cost 3D Scanning Techniques for Cultural Heritage Documentation. The International Archives of the Photogrammetry, Remote Sensing and Spatial Information Sciences.Vol. XXXVII. Part B5. Beijing

[8] Pavelka, K., Řezníček, J., Bílá, Z. 2013, Non-invasive and non-contact prospection of archaeological and historici objels. STEF92Technology Ltd., Bulgaria, 13th International Multidisciplionary Scientific Geoconference SGEM 2013, Albena, Conference Proceedings Vol.II., ISBN 978-619-7105-01-8, ISSN 1314-2704, DOI: 10.5593/sgem2013, p.647654

[9] Fraštia, M., Marčiš, M., Haličková, J., Chlepková, M. 2011. Využitie fotogrametrického a laserového skenovania na dokumemtáciu objektov banskoštiavnickej kalvárie. Almanach znalca : pre znalcov v odbore stavebníctvo Roč.10, č. 4. s. 11--16. ISSN 1336-3174.

[10] Fraštia, M., Marčiš, M., Haličková, J.,Chlepková, M. 2012. Optické a laserové skenovanie banskoštiavnickej Kalvárie. Pamiatky a múzeá : revue pre kultúrne dedičstvo Roč.61, č.4. s. 64--66. ISSN 1335-4353.

[11] Hanzalová, K., Pavelka, K., 2013. Documentation and Virtual Reconstruction of Historical Objects in Peru Damaged by an Earthquake and Climatic Events, Special Issue: 8th EGU Alexander von Humboldt Conference "Natural Disasters, Global Change, and the Preservation of World Heritage Sites", ADGEO, Cuzco, Peru, 2012. Adv. Geosci., 35, 67-71, 2013, doi:10.5194/adgeo-35-67-2013, http://www . adv-geosci.net/35/67/2013/

\section{References from websites}

[12] ARC 3D Webservice [online]. <http://homes.esat.kuleuven.be/ \{\}visit3d/ webservice/v2/ >. [cit.5-10-2013]. 
[13] Mach, J. 2009. Insight 3D : open source image based 3d modelling software [online]. < http://insight3d.sourceforge.net/ $>$ [cit.15-11.2013].

[14] MeshLab. 2013. [online]. <http://meshlab. sourceforge.net>. [cit.14-1.2013].

[15] PhotoModeler Scanner - 3D Scanner for dense surface 3d scanning [online], <http: //www. photomodeler.com/products/pm-scanner.htm>.[cit.15-2-2013].

[16] Microsoft Corporation Photosynth. 1997. [online]. Use your camera to stitch the world [online], last updated 2003-26-04. <http://photosynth.net/>.[cit.15-2-2012]. 